\title{
Level of Knowledge and Compliance of Mexican Food Code among Hospital Foodservice Employees in Guadalajara, México
}

\author{
Elsa Ramírez, Josefina Linerio, Patricia Chombo, René Jasso, Sandra Bravo, Hearan L. Ashraf \\ Food Safety Training Group, Centro de Investigación y Asistencia en Tecnología y Diseño del Estado de Jalisco A.C., Guadalajara, \\ México. \\ Email: hlashraf@gmail.com
}

Received July $12^{\text {th }}, 2011$; revised August $26^{\text {th }}, 2011$; accepted September $4^{\text {th }}, 2011$.

\begin{abstract}
Contamination of food may occur at any point during the food distribution channel. However, mishandling of food at the last segment of food distribution where food is prepared for consumption often causes outbreaks. Keeping food safe in hospitals is particularly imperative because of the population they serve and the potentially hazardous environment. This article presents the results of a pencil and paper self-reported survey on the knowledge of Mexican food code, NOM-093-SSA1-1994, and field observation of the compliance of the code among the hospital foodservice employees in Guadalajara, México. One hundred twenty-seven employees from six public and private hospitals participated in the study. Of the respondents, $81.5 \%$ were aware of the importance of personal hygiene in food safety. Professional attire including hair restraints and mouth cover were always used. These participants, however seldom used thermometers, and only $37 \%$ of respondents knew the correct temperatures for refrigeration. In most hospitals correct procedures for sanitizing food contact surfaces that were prescribed by the sanitizing chemical manufacturers were practiced. Only $25 \%$ of the participants knew that their work was defined by the food code. Strategies for dissemination of the food code, and food safety training of the employees are urgently needed. Commitment and support of the hospital are needed in order to improve safe food handling practices in these hospitals.
\end{abstract}

Keywords: Hospital Foodservice, Food Hygiene, Food Sanitation, Food Code, Food Regulation, Food Safety Training, Hazard Analysis and Critical Control Point

\section{Introduction}

Foodborne illness is increasingly recognized as a serious public health challenge globally. Accurate accounts for global incidence of foodborne disease are not available, however, it is reported that 1.8 million people died from diarrheal diseases in 2005 alone, mainly due to contamination of food and drinking water [1]. A most recent US estimate indicates that each year one out of six Americans (48 million people) get sick, 128,000 hospitalized, and 3000 die from foodborne illness [2]. In México food safety is relevant for various national agendas including public health, international trade, tourism, agricultural production, and national productivity [3].

A large portion of foodborne outbreaks is attributed to the poor handling of food at the food preparation stage in Latin American countries, and in the US nearly $40 \%$ is attributed to foodservice operations [4,5]. It is especially important to require stringent control over safe food handling for hospital foodservices, because they serve the most vulnerable populations with impaired immunity and the possibility of infectious situations in general. Unfortunately numerous reports show that foodborne outbreaks in hospitals are often caused by inadequate food handling $[6,7]$.

International organizations such as Pan American Health Organization (PAHO), World Health Organization (WHO) and Food and Agriculture Organization (FAO) have developed strategies and recommendations for food control system over several decades [8,9]. For hospitals, Joint Commission International for Accreditation and Certification (JCI) provides internationally participated programs for quality care and patient safety [10].

In México, "Programa H", the first national food safety program for foodservice establishments was initiated 
in 1988 [11]. This program was changed to "Distintivo $\mathrm{H}$," which was eventually elevated to a food standard as NMX-F-605-NORMEX-2004. Voluntary in nature, this standard is administered by the Ministry of Tourism, and requires a certification for food handling training for employees and annual verification of the sanitary operation of the establishment. On the other hand, the Ministry of Economy developed mandatory regulations of similar scope. Mexican food code NOM-093-SSA1-1994, which affected the retail establishments where food and beverages were prepared and served, went into effect in 1996 [12]. This regulation covered several aspects of foodservice operation; receiving of the incoming materials, storage, food handling and cooking, handling of utensils and equipment, maintenance of installations and facilities, handling of ready-to-eat food, potable water and ice, pest control and waste, personal hygiene, transportation of food, and monitoring and self verification of the safe operation.

The Objectives of this study were to measure the levels of basic food safety knowledge among hospital foodservice employees in Guadalajara, México, and their compliance of the national food code. It was hoped that the information compiled in this study may be valuable in future endeavors of implementing HACCP programs in the hospitals of the region.

\section{Materials and Methods}

\subsection{Participating Hospitals}

An invitation to participate in the project was sent to all private hospitals (total of 49) and four public hospitals in Guadalajara. For the hospitals interested, an intake telephone interview was carried out to obtain information including number of beds, number of employees, types of services offered, and the existence of training programs for their employees and the use of food safety manuals.

\subsection{Employees Participated in Knowledge Survey}

Each hospital selected participants for the survey among the employees in various positions. The survey took place at a conference room in Centro de Investigación y Asistencia en Tecnología y Diseño del Estado de Jalisco, A. C. in Guadalajara, except that the public hospital survey took place at the hospital training facility.

\subsection{Instrument for the Knowledge Survey}

A questionnaire pertaining demographic information and 18 statements regarding the specific key food handling procedures described in NOM-093-SSA1-1994 was con- structed by the project team members. This questionnaire was modeled after several questionnaires used in similar studies reported [13-16].

\subsection{Field Observation}

A field observation was carried out by two project members (total 6 members) for each hospital. During the observation, employees were observed for 36 procedures described in the NOM-093-SSA1-1994. Generally, it took 2 to 4 hours to complete an observation.

\subsection{Data Analysis}

Descriptive statistics were used for the summaries of characteristics of hospitals and the survey participants. The effects of the demographic variables on the level of knowledge was determined by Analysis of Variance and Least Significant Difference test $(p \geq 0.05)$ using STATGRAPHIC Centurion ${ }^{\circledR}$ software [17].

\section{Results}

\subsection{Characteristics of the Participating Hospitals}

Five private hospitals with numbers of beds between 25 and 110 , and a public hospital with 1000 beds participated in this project (Table 1). The responsible persons for the foodservice operation were identified as nutritionists, hospital administrators, and foodservice managers. Apart from the meal service to the patients, all the hospitals provided one or more of the following services; special meals for medical staff, cafeteria for staff and visitors, a restaurant with wait staff, room service, and meals for other organizations. None of the hospitals had a complete sanitation manual for the entire areas of operation, but all the respondents said that their operations adopted NOM-093-SSA1-1994. None of the hospitals was certified for "Distintivo H," but, one hospital provided training in "Distintivo H" for all the kitchen staff in the past without certification, and another hospital was preparing for the certification at the time of this project. None had a HACCP plan developed for its operation.

\subsection{Demographic Characteristics of the Participants}

The number of participants from each hospital varied between 2 to 7 for private hospitals and 100 for the public hospital (total 127). Out of 118 returned questionnaires, 98 were usable for this report (Table 2). Job titles of the participants included hospital administrator, nutritionist, supervisor, cook, cook's helper, dishwasher, meal delivery staff, and wait staff. The most common position was cook's helper. Years of experience ranged between 
Table 1. Characteristics of the participating hospitals.

\begin{tabular}{|c|c|c|}
\hline Characteristics & No. $(n=6)$ & \\
\hline \multirow{2}{*}{ Type of hospital } & Private & 5 \\
\hline & Public & 1 \\
\hline \multirow{4}{*}{ No. of beds } & $25-50$ & 3 \\
\hline & $51-100$ & 1 \\
\hline & $101-150$ & 1 \\
\hline & $>1000$ & 1 \\
\hline \multirow{3}{*}{$\begin{array}{l}\text { No. of foodservice } \\
\text { employees }\end{array}$} & $5-10$ & 3 \\
\hline & $11-15$ & 2 \\
\hline & $>100$ & 1 \\
\hline \multirow{3}{*}{$\begin{array}{l}\text { Person in charge of } \\
\text { foodservice operation }\end{array}$} & Hospital administrator & 2 \\
\hline & Nutritionist & 3 \\
\hline & Foodservice supervisor & 1 \\
\hline \multirow{5}{*}{$\begin{array}{l}\text { Types of services } \\
\text { offered }\end{array}$} & Patient meals & 6 \\
\hline & Meals for medical staff & 4 \\
\hline & Cafeteria for staff and visitors & 2 \\
\hline & Restaurant \& room service & 1 \\
\hline & Special event & 3 \\
\hline \multirow{5}{*}{$\begin{array}{l}\text { Have the following } \\
\text { manuals }\end{array}$} & Personal hygiene & 4 \\
\hline & Purchasing & 3 \\
\hline & Storage & 3 \\
\hline & Food preparation & 4 \\
\hline & Cleaning and sanitation & 2 \\
\hline \multirow{2}{*}{$\begin{array}{l}\text { Food safety training } \\
\text { for staff }\end{array}$} & Yes & 2 \\
\hline & No & 4 \\
\hline NOM-093-SSA1-1994 & Adopted & 6 \\
\hline \multirow{2}{*}{ "Distintivo H" } & Certified & 0 \\
\hline & Under preparation & 2 \\
\hline
\end{tabular}

" $<2$ years" and ">20 years" and were somewhat evenly distributed within this range. Age was also evenly distributed between 20 and 65. Education level also showed a somewhat even distribution among elementary school ( $<6$ years), secondary school (6 - 9 years), and high school (10 - 12 years). A small number of participants attended technical schools and professional programs.

\subsection{Effect of Demographic Variables on the Level of Knowledge}

As shown in Table 2, the high individual variations in scores for the 18 food safety statements resulted in large standard deviations for the means. In terms of the positions of the participants, nutritionists scored highest with a 73.2\% mean correct responses. The title "dietitian" pertained rather different responsibilities among the participants in this study than the "dietitians" in other countries where it is the title for a professional who is often responsible for clinical aspect of diet for patients. In this study dietitians reported to foodservice supervisors and were responsible for the delivery of trays delivered to the correct patients. Their knowledge level was not as high as foodservice supervisors or cooks. Age, gender, years of experience or schooling was not significantly related to the level of knowledge of the participants. It was noticeable that the mean score for the employees of private hospitals was 10 point higher than that of the employees of public hospital. However, the variations in both groups were extremely high.

\subsection{Participants' Level of Knowledge Regarding Safe Food Handling}

Among five key food-handling areas in the questionnaire (Table 3), the highest level of correct responses was found in personal hygiene $(83.2 \%)$. All but one participant said they knew the importance of hand washing. The majority of the participants $(82.3 \%)$ knew the procedures preventing cross-contamination. However, only $40 \%$ of respondents knew that it is required to use a thermometer to monitor temperatures of potentially hazardous food (PHF) during food handling. About 31\% of the participants said they knew the final minimum internal cooking temperatures of PHF. Furthermore, only $37.1 \%$ of the respondents knew the required refrigeration temperature, and only $25.5 \%$ knew that their daily work activities were described in nation's regulation.

\subsection{Field Observation of the Operation}

As shown in Table 4, the most outstanding but basic deficiency was the absence of hand washing stations in the food preparation area. Only two out of four hospitals had the hand washing sink within the food prep area. The work attire of the workers including uniforms and hair and mouth coverings was kept in clean and well-maintained condition. Generally storage management principles such as "First-In, First-Out" method are seldom practiced, and cleaning and sanitizing chemicals werestored in the same area with foodstuff. Preventive pro- 
Table 2. Demographic characteristics of the participating employees and their knowledge level.

\begin{tabular}{|c|c|c|c|}
\hline & & No. $(n=98)$ & Scores ( $\%$ correct response) Mean \pm Std. Dev. \\
\hline \multirow{9}{*}{ Position } & Administrator & 1 & $61.1 \pm 0.00^{\mathrm{abcd}}$ \\
\hline & Nutritionist & 6 & $73.2 \pm 12.38^{\mathrm{a}}$ \\
\hline & Supervisor & 3 & $70.4 \pm 19.51^{\mathrm{abc}}$ \\
\hline & Dietitian & 10 & $57.2 \pm 24.57^{\mathrm{abc}}$ \\
\hline & Cook & 16 & $63.2 \pm 17.20^{\mathrm{ab}}$ \\
\hline & Cook's helper & 49 & $51.7 \pm 14.23^{\mathrm{c}}$ \\
\hline & Storeroom steward & 1 & $50.0 \pm 0.00^{\mathrm{abcd}}$ \\
\hline & Dish washer & 1 & $33.3 \pm 0.00^{\mathrm{bcd}}$ \\
\hline & Other: distributor, server & 11 & $39.5 \pm 15.15^{\mathrm{d}}$ \\
\hline \multirow{5}{*}{ Years of experience } & $>2$ & 17 & $53.0 \pm 13.26$ \\
\hline & $2-7$ & 27 & $52.6 \pm 19.00$ \\
\hline & $8-13$ & 29 & $61.7 \pm 18.77$ \\
\hline & $14-19$ & 9 & $52.8 \pm 15.43$ \\
\hline & $>20$ & 15 & $53.6 \pm 18.42$ \\
\hline \multirow{4}{*}{ Age } & $20-30$ & 21 & $57.6 \pm 13.46$ \\
\hline & $31-40$ & 30 & $58.2 \pm 18.20$ \\
\hline & $41-50$ & 27 & $54.8 \pm 17.37$ \\
\hline & $>51$ & 20 & $49.3 \pm 15.25$ \\
\hline \multirow{2}{*}{ Gender } & Male & 38 & $55.4 \pm 18.45$ \\
\hline & Female & 60 & $54.5 \pm 17.56$ \\
\hline \multirow{5}{*}{ Position } & Elementary $(<6)$ & 24 & $51.6 \pm 18.65^{\mathrm{a}}$ \\
\hline & Middle school (6 - 9) & 31 & $50.9 \pm 19.26^{\mathrm{a}}$ \\
\hline & High school $(9-12)$ & 25 & $53.2 \pm 18.30^{\mathrm{a}}$ \\
\hline & Technical degree $(9-12)$ & 6 & $64.3 \pm 14.05^{\mathrm{ab}}$ \\
\hline & Professional degree $(12-16)$ & 12 & $65.7 \pm 13.96^{\mathrm{ab}}$ \\
\hline \multirow{2}{*}{ Type of hospital employed } & Private & 28 & $61.7 \pm 26.27^{\mathrm{a}}$ \\
\hline & Public & 70 & $51.7 \pm 27.36^{\mathrm{a}}$ \\
\hline
\end{tabular}

abcd: The means with the same subscript are not significantly different at $p \leq 0.05$ by Least Significant Difference Test.

cedures for cross-contamination as well as disinfecting fresh produce were well practiced in most hospitals. Thermometers are seldom used in most of the operations to monitor final internal minimum cooking temperatures or to maintain the temperature of the refrigerators or holding equipment. Another overlooked practice is sanitizing tableware and eating utensils. The majority of the hospitals did not measure the amount of the sanitizing solutions or follow correct procedures specified by the manufacturers as described in the food code.

\section{Discussion}

Three major risk factors identified by the field observations of the operations were: 1) Lack of hand washing stations in the food preparation area, 2) Failure of maintaining the refrigeration temperature at or below $7^{\circ} \mathrm{C}$, and 3) Failure to clean and sanitize food contact areas correctly including patient tableware and eating utensils. All 
Table 3. Survey results of the participants' knowledge on safe food handling procedures described in NOM-093-SSA1-1994.

\begin{tabular}{|c|c|c|c|c|}
\hline & \multirow{2}{*}{ Questions } & \multicolumn{3}{|c|}{ \# of Responses $(\mathrm{n}=98)$} \\
\hline & & Correct & Incorrect & Don't know \\
\hline \multirow{4}{*}{$\begin{array}{l}\text { Personal } \\
\text { hygiene }\end{array}$} & I use my fingers to handle ready-to-eat food. & 85 & 12 & 1 \\
\hline & I keep my finger nails polished because they do not pose any risk to safety of food. & 82 & 10 & 6 \\
\hline & When I have diarrhea I should not report to work or handle food at work. & 62 & 29 & 7 \\
\hline & Mean/\% & $81.5 / 83.2 \%$ & $12.8 / 13.6 \%$ & $3.8 / 3.9 \%$ \\
\hline \multirow{3}{*}{$\begin{array}{l}\text { Cross- } \\
\text { contamination }\end{array}$} & $\begin{array}{l}\text { I use same cutting board to cut raw meat and then salad ingredients without washing } \\
\text { and sanitizing. }\end{array}$ & 80 & 13 & 4 \\
\hline & I use same cutting board for raw meat as well as cooked meat without washing. & 86 & 7 & 4 \\
\hline & Mean/\% & $80.7 / 82.3 \%$ & $11.3 / 11.5 \%$ & $4.3 / 4.4 \%$ \\
\hline \multirow{5}{*}{$\begin{array}{c}\text { Final } \\
\text { minimum } \\
\text { internal cooking } \\
\text { temp for } \mathrm{PHF}\end{array}$} & I use thermometer to measure the temperature of meat when I cook at work. & 39 & 38 & 20 \\
\hline & The final cooking temperature for poultry is $74^{\circ} \mathrm{C}$. & 33 & 19 & 43 \\
\hline & The final cooking temperature for ground meat is $68^{\circ} \mathrm{C}$. & 23 & 22 & 50 \\
\hline & The final cooking temperature for fish is $63^{\circ} \mathrm{C}$. & 26 & 19 & 50 \\
\hline & Mean/\% & $30.5 / 31.1 \%$ & $24.5 / 25 \%$ & $40.8 / 41.6 \%$ \\
\hline \multirow{5}{*}{$\begin{array}{l}\text { Temperature } \\
\text { danger zone } \\
\text { for PHF }\end{array}$} & When holding hot food, the temperature of food needs to be maintained at $60^{\circ} \mathrm{C}$. & 48 & 13 & 34 \\
\hline & When holding cold food, the temperature of food needs to be maintained at $7^{\circ} \mathrm{C}$. & 43 & 20 & 32 \\
\hline & I keep cooked or leftover foods on the counter for one day as long as it is covered. & 71 & 18 & 6 \\
\hline & I keep the temperature of the refrigerators at my work at $7^{\circ} \mathrm{C}$ at all times. & 36 & 31 & 28 \\
\hline & Mean/\% & $44.8 / 45.7 \%$ & $26.8 / 27.3 \%$ & $23.4 / 23.9 \%$ \\
\hline \multirow{3}{*}{$\begin{array}{l}\text { Food safety } \\
\text { regulations }\end{array}$} & $\begin{array}{l}\text { The regulation regarding safe food handling at my work is defined by the food code, } \\
\text { NOM-093-SSA1-1994 }\end{array}$ & 25 & 11 & 59 \\
\hline & Are you familiar with "Distintivo H”? (yes, or no) & 25 & - & 70 \\
\hline & Mean/\% & $25 / 25.5 \%$ & $5.5 / 5.6 \%$ & $64.5 / 65.8 \%$ \\
\hline
\end{tabular}

of these three procedures are fundamental safe food handling procedures that are prescribed in Mexican food code NOM-093-SSA1-1994.

In terms of hand washing practice, all the participants in this study knew that hand washing is important for food safety; however, it is difficult to practice frequent hand washing while working in the food prep area due to absence of hand washing sink. This problem has been reported in similar studies from other countries where kitchen infrastructures are not up to date [14]. Campaigns to reduce infection by frequent hand washing in health care facilities and foodservices are advocated globally $[10,18,19]$.
Another important personal hygiene practice is not to report to work when one has diarrhea. In this study one third of the respondents did not know this requirement. There may be various factors related to this problem; not being able to find a substitute worker on the part of managers, and/or not willing to lose the day's wage on the part of the employees.

The range of refrigerator temperatures observed in this study was $5^{\circ} \mathrm{C}-10^{\circ} \mathrm{C}$, with only 2 hospitals keeping their refrigerator under $7^{\circ} \mathrm{C}$. The simple essential rule of food safety, "time and temperature principle" of microbial growth should be emphasized to these participants. In the US where foods are frequently prepared in large quantity 
Table 4. Summary of field observation of food handling practice described in NOM-093-SSA1-1994.

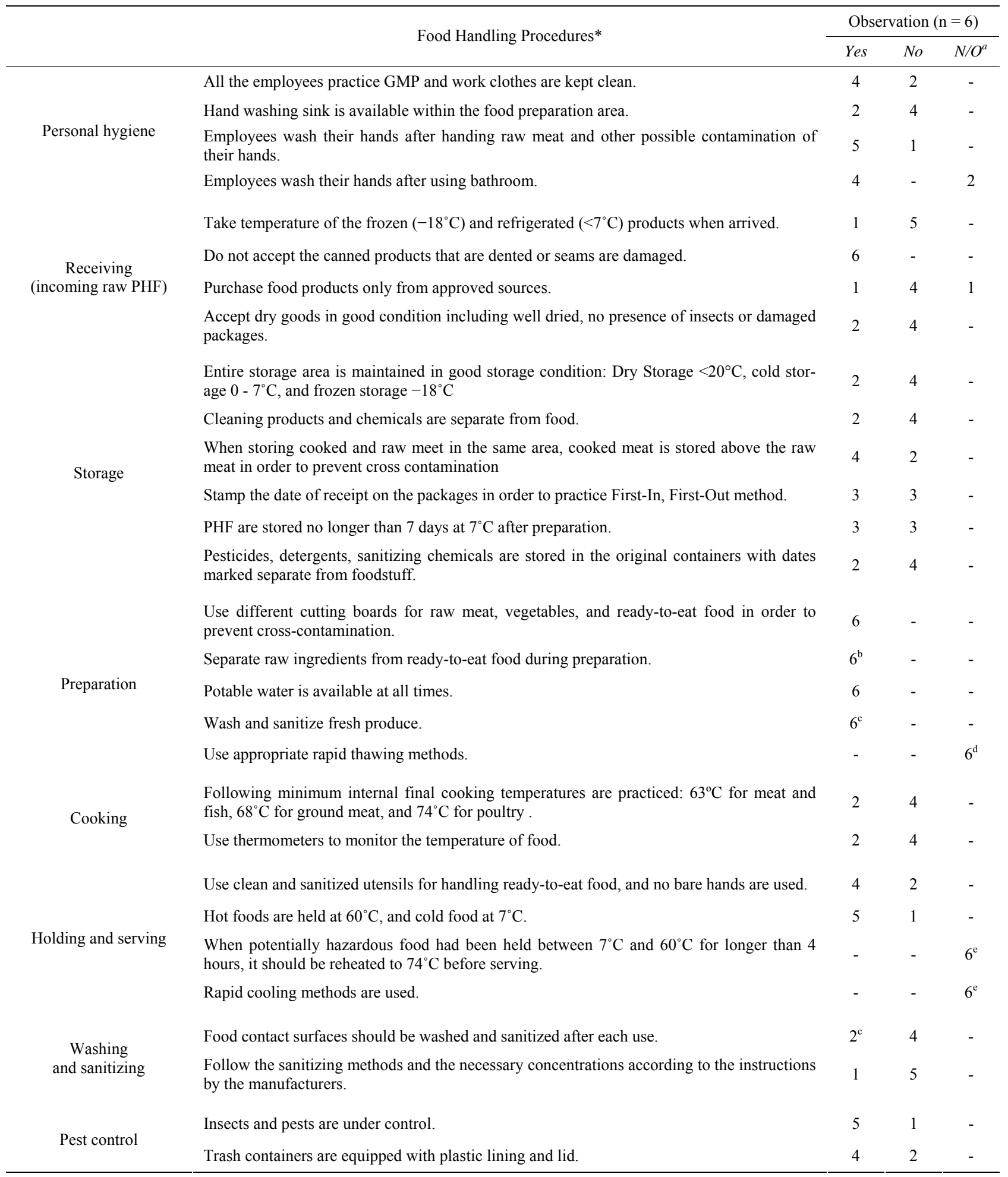

*The original observation form had 36 items. Some with similar components are omitted in this table; ${ }^{\mathrm{a}}$ Not Observed; ${ }^{\mathrm{b}}$ Even if practiced, consistent practice was not observed; ${ }^{\mathrm{c}}$ Although sanitizing was practiced, the concentrations of the chemicals are not measured nor monitored. Methods of washing and disinfecting were not consistent with the recommendations from the manufacturers; ${ }^{\mathrm{d}}$ Most of the hospitals used fresh meat rather than frozen meat. Therefore not much thawing was practiced; ${ }^{\mathrm{e}}$ Generally foods are prepared on the same day as consumption. Therefore cooling or reheating processes were not applicable for these facilities. Leftovers were often given away or discarded. 
and held over longer than 6 hours, failure of proper cold holding of potentially hazardous food was found to be the most frequent cause of foodborne illness outbreaks in retail establishments [20]. However, most of the hospitals participated in this study were using the food production system of "Preparation for same day service." This system renders food handling simple without the necessity of cooling, holding, or reheating of the prepared food [21].

Another area of observation was cleaning and sanitizing food contact areas. The absence of appropriate cleaning and sanitizing procedures for tableware and eating utensils in these hospitals raised concern, because according to a US Food and Drug Administration (FDA) study, the second most prevalent risk for the foodborne illness outbreaks reported was the failure of cleaning and sanitizing surfaces/utensils [20]. For most of the sanitizing chemicals sold in the market, a three-compartment sink is recommended for a three-step procedure, namely, wash, rinse and sanitize. This system assures the proper sanitizing process because the presence of organic matter reduces the effectiveness of the sanitizing agent, especially chlorine-based agents which are the most frequently used in the food industry. In situations where three-compartment sinks are not available, improvisations to simulate the three-step process can be made to assure the effectiveness of the sanitizing agents [20]. However, in four of the six participating hospitals, the disinfecting agent was added to the wash water along with detergent in the first tank, and then rinsed off in the second tank.

Also noted was that these hospitals did not measure the sanitizing chemicals, just as the observation reported in a study in Turkey [15]. Therefore in some cases concentrations in the wash tank were much higher than the recommendations (50 - $100 \mathrm{ppm}$ chlorine, $12.5 \mathrm{ppm}$ for iodine, and colloidal silver). In one case, disposable tableware and eating utensils were used in order to eliminate ware-washing procedure. This method, albeit convenient, raises concerns for environmental issues.

An additional problem identified was the lack of purchasing and receiving programs that may foster food safety. The suppliers are often small operations, and delivery is frequently informal. Inspection at the time of delivery is not often practiced. It will be necessary for these hospitals to set up purchasing policies, or quality standards to receive safe food supplies. Receiving procedures for raw materials should also be set up to include visual inspection, temperature measurement, and other methods of quality testing for potentially hazardous ingredients before the materials enter the operation.

The knowledge level of the participants varied with the area of operation. Personal hygiene procedures such as the importance of hand washing and use of clean work attire and hair and mouth covering are well understood and impeccably practiced among these respondents. More technical information such as the temperature requirements, however, is poorly known. In general the current findings are in agreement with the studies carried out in Italy, Turkey, and Iran as well as in the US [13-16, 22-24].

\section{Conclusions}

The findings of this study delineated the areas that need training for the hospital food-handlers in order for them to practice satisfactory food safety control measures. As indicated in the current study and the studies from other countries, elevating the level of food safety knowledge and practice among the foodservice employees is urgently needed.

Strong leadership and employee supportive style of management that foster good hygiene practice are necessary for the success of employee training. Particularly, the emphasis should be placed on the hospital administration to provide necessary resources. Often proper physical facilities such as a refrigerator that keeps the temperature below $7^{\circ} \mathrm{C}$ and the hand-washing sink near food preparation area, are needed to practice good hygiene and comply the regulations.

On March 1, 2010, Secretary of Health of México announced an upcoming new food code, NOM-251-SSA12009, Hygiene practice for food, beverage and supplement processes. This code replaced the NOM-093, and became effective on December 17, 2010 [25]. The NOM251 contains an additional section on employee training including personal hygiene, natures of food products, preparation methods and the associated contamination possibilities, degree of processing after the preparation and before the final consumption, reception and storage of the raw ingredients, the expected length of time before consumption, repercussion of contaminated product in the consumer's health, and knowledge of the food code. Another important inclusion in the NOM-251 is the provision for HACCP. The findings reported in this article may serve as bases for developing effective training materials aimed at the front-line foodservice employees, and strategies for implementing a HACCP program. Food code provides standards for the foodservice operators to confirm. Inclusive food code combined with regular inspection for guidance and surveillance is the key to the national food safety.

Each year millions of foodborne illness cases and outbreaks result from various biological agents including rotavirus, Salmonella spp, E. coli, Campylobacter jejuni, 
Shegella spp, Listeria monocytogene, and Giardia lambilia, to name a few. These agents can be effectively controlled by the application of time and temperature principle, proper personal hygiene, and protection of equipment from contamination. Training of food handlers on these technical principles should be essential for combating foodborne illness. Nationwide dissemination of food code and employee training are the primary steps in food safety in these hospitals and beyond.

\section{Acknowledgements}

The authors express sincere appreciation to Dr. Héctor Escalona Buendía for statistical analysis, and to Mr. Winston Smith for manuscript preparation.

\section{REFERENCES}

[1] World Health Organization, "Food Safety and Foodborne Illiness," Fact Sheet No. 237, Geneve, 2007. http://www.who.int/mediacentre/factsheets/fs237/en/

[2] Center for Disease Control and Prevention, "Estimates of Foodborne Illness in the United States," Atlanta, 2011. http://www.cdc.gov/foodborneburden/index.html

[3] J. L. F. Luna and A. V. Méndez, "Communication and participation. The experience in México," Proceedings of FAO/WHO Global Forum of Food Safety Regulators, Appendix XII Agenda item 4.4, Marrakesh, 28-30 January 2002.

http://www.foodsafetyforum.org/global/index_en.htm

[4] Institute of Nutrition of Central America and Panama (INCAP), "The 5 Key Ways to Keep Your Food Safe (Content Manual)," PAHO/INCAP, Guatemala, 2006. http://www.paho.org/English/AD/DPV/VP/fos-5-clavesmanual.htm.

[5] Center for Disease Control and Prevention, "Surveillance for Foodborne Disease Outbreaks-United States, 19881992," Morbidity and Mortality Weekly Report, Vol. 45, No. SS-5, 1996, pp.1-66.

http://www.cdc.gov/mmwr/preview/ind1996_ss.html

[6] M. R. Evans, P. G. Hutchings, C. D. Ribeiro and D. Westmoreland, "A Hospital Outbreak of Salmonella Food Poisoning due to Inadequate Deep-Fat Frying," Epidemiology and Infection, Vol. 116, No. 2, 1996, pp. 155-160. http://www.jstor.org/pss/3864612 doi:10.1017/S0950268800052389

[7] P. W. Collier, J. C. Sharp, A. F. MacLeod, G. I. Forbes and F. Mackay, "Food Poisoning in Hospitals in Scotland, 1978-1987," Epidemiology and Infection, Vol. 101, No. 3, 1988, pp. 661-667.

http://www.ncbi.nlm.nih.gov/pmc/articles/PMC2249422/ doi:10.1017/S095026880002954X

[8] Codex Alimentarius Commission, "Codex AlimentariusJoint FAO/WHO Food Standards," FAO, Rome, 1963. http://www.codexalimentarius.net/download/standards/

[9] FAO/WHO Secretariat, "Strengthening Official Food Safety
Control Services," Working Papers of the Second FAO/ WHO Global Forum of Food Safety Regulators, FAO, Rome, 2004

http://www.fao.org/docrep/meeting/008/y5871e/y5871e0 0.HTM

[10] Joint Commission International on Accreditation and Certification, "The International Essentials of Health Care Quality and Patient Safety ${ }^{\text {TM, }, ~ S i n g a p o r e, ~} 2011$.

http://www.jointcommissioninternational.org/Internationa 1-Essentials-for-Quality-and-Patient-Safety/

[11] Sociedad Mexicana de Normalización y Certificación S.C., "NMX-F-605-NORMEX-2004, Alimentos-Manejo higié-nico en el servicio de alimentos preparados para la obtención del Distintivo H," Distrito Federal, Mexico, 2004.

http://www.normex.com.mx/manejo-higienico-de-aliment os

[12] Secretaría de Salud, "Norma Oficial Mexicana NOM093-SSA1-1994, Bienes Y Servicios. Prácticas de higiene y sanidad en la preparación de alimentos que se ofrecen en establecimientos fijos," Distrito Federal, 1995. http://www.salud.gob.mx/unidades/cdi/nom/093ssa14.ht $\mathrm{ml}$

[13] I. F. Angelillo, N. M. A. Viggiani, R. M. Greco and D. Rito, "The Collaborative Group. HACCP and food hygiene in hospital: Knowledge, attitudes, and practices of foodservices staff in Calabria, Italy," Infection Control and Hosp. Epidemiology, Vol. 22, No. 6, 2001, pp. 363369. http://www.jstor.org/stable/30141463

[14] M. Askarian, G. Kabir, M. Amin Baig, Z. A. Memish and P. Jafari, "Knowledge, Attitudes, and Practices of FoodService Staff Regarding Food Hygiene in Shiraz, Iran," Infection Control and Hospital Epidemiology, Vol. 25, No. 1, 2004, pp. 16-20. doi:10.1086/502285

[15] M. Bas, M. A. Temel, A. S. Ersun and G. KivanÇ, "Prerequisite Programs and Food Hygiene in Hospitals: Food Safety Knowledge and Practices of Foodservice Staff in Ankara, Turkey," Infection Control and Hosp Epidemiology, Vol. 26, No. 4, 2005, pp. 420-424.

http://www.jstor.org/stable/10.1086/502562

[16] H. L. Ashraf, D. Blaise, J. Bloom, S. Atwood and J. Salazar, "Efficacy of HACCP-Based Food Handling Training Program for Front-Line Foodservice Workers," Journal of Culinary Science and Technology, Vol. 6, No. 1, 2008, pp. 63-76. doi:10.1080/15428050701884204

[17] Statgraphics, "Centurion XV Version 15.2.06. 1982-2007," StatPoint, Inc., Herndon, 2007.

[18] L. R. Green, C. A. Selman, V. Radke, D. Ripley, J. C. Mack, D. W. Reimann, T. Stigger, M. Motsinger and L. Bushnell, "Food Worker Hand Washing Practices: An Observation Study," Journal of Food Protection, Vol. 66, No. 10, 2006, pp. 2417-2423.

[19] World Health Organization, "Action on Patient SafetyHigh 5s. Patient safety," Geneve, 2006.

http://www.who.int/patientsafety/solutions/high5s/en/inde x.html. 
[20] Retail Food Program Steering Committee, Center for Food Safety and Applied Nutrition, "Report of the FDA Retail Food Program Database of Foodborne Illness Risk Factors," US FDA, College Park, 2000.

[21] Center for Food Safety and Applied Nutrition, "Applying HACCP Principles to Retail and Foodservice. Ch. 2. The Process Approach: Managing Food Safety: A Manual for the Voluntary Use of HACCP Principles for Operators of Foodservice and Retail Establishments," US FDA, College Park, 2006.

[22] V. S. C. Gallegos and B. R. Lugo, "Análisis de los estándares de calidad en el manejo higíenico de los alimentos en seis hoteles de la Ciudad de Puebla (Tesis profesional)," Universidad de las Américas, Puebla, México, 2004.

[23] B. Tokuc, G. Ekuklu, U. Berberoglu, E. Bilge and H.
Dedeler, "Knowledge, Attitudes and Self-Reported Practices of Foodservice Staff Regarding Food Hygiene in Edurne, Turkey," Food Control, Vol. 20, No. 6, 2009, pp. 565-568. doi:10.1016/j.foodcont.2008.08.013

[24] C. Buccheri, C. Mammina, S. Giammanco, M. Giammanco, M. La Guardia and A. Casuccio, "Knowledge, Attitudes and Self-Reported Practices of Food Service Staff in Nursing Homes and Long-Tern Care Facilities," Food Control, Vol. 21, No. 10, 2010, pp. 1267-1373. doi:10.1016/i.foodcont.2010.04.010

[25] Secretaria de salud, "Norma Oficial Mexicana NOM-251SSA1-2009, Prácticas de hygiene para el proceso de alimentos, bebidas o suplementos alimenticios," Secretaría de Salud, Distrito Federal, Mexico, 2010. http://www.dof.gob.mx/documentos/3980/salud/salud.htm 